\title{
IMPACTOS DA GREVE DOS CAMINHONEIROS À LUZ DO CÓDIGO DE DEFESA DO CONSUMIDOR
}

\author{
Damiana Hernestina Alves* \\ Laine Alves Assis \\ Vanessa Érica da Silva Santos* \\ Fernanda Beatryz Rolim Tavares ${ }^{* * *}$
}

\begin{abstract}
RESUMO
O presente trabalho tem por intento analisar as práticas abusivas ocorridas durante a greve dos caminhoneiros deste ano de 2018 à luz da Lei ${ }^{\circ}$ 8.078, de 11 de setembro de 1990 ou Código de Defesa do Consumidor e analisar as práticas abusivas cometidas pelos postos de combustíveis e como tais práticas afetaram o meio social. Também buscou-se analisar os princípios constitucionais que regem a matéria, bem como o trabalho de pesquisadores e economistas cerca da matéria. Ao verificar as práticas abusivas contra os consumidores no período crítico da greve e as ilegalidades que ocorreram durante o período, e buscando em específico trabalhar a questão de um ponto de vista mais regional, ou seja, no município de Sousa. E tendo em vista que os ocorridos localmente também foram realizados em âmbito regional e nacional, a questão aqui trabalhada abarca uma realidade muito mais ampla.
\end{abstract}

PALAVRAS-CHAVE: Preço dos Combustíveis; Proteção Consumerista; Impactos Sociais.

* Graduanda do Curso de Direito pela Universidade Federal de Campina Grande. email:damianaalves555@gmail.com.

** Graduanda do Curso de Direito pela Universidade Federal de Campina Grande. email: laine.alvesassis@gmail.com.

*** Graduada em Ciências Jurídicas e Sociais pela Universidade Federal de Campina Grande (UFCG), Especialista em Direito do Trabalho pela UNOPAR, Pósgraduanda (especialização) em Direito Penal e Processo Penal pela UFCG, Pósgraduanda (especialização) em Gestão Pública pelo IFPB e Mestranda em Sistemas Agroindustriais - CCTA/UFCG, Professora Substituta da UFCG.

*** Graduada em Ciências Contábeis pela Universidade Federal de Campina Grande (UFCG), Especialista em Gestão Ambiental pela UFCG, Pós-graduanda (especialização) em Gestão Pública pelo IFPB, Pós-graduanda (especialização) em Contabilidade para Gestão Pública e Empresarial. Mestre em Sistemas Agroindustriais - CCTA/UFCG. 


\begin{abstract}
The present work is intended to analyze the abusive practices that occurred during the strike of the truck drivers of this year of 2018 in light of Law n ${ }^{\circ}$ 8.078, of September 11, 1990 or Code of Consumer Protection and analyze the abusive practices committed by the gas stations and how such practices affected the social environment. We also sought to analyze the constitutional principles governing the subject, as well as the work of researchers and economists around the subject. When verifying abusive practices against consumers during the critical period of the strike and the illegalities that occurred during the period, and looking specifically to work the issue from a more regional point of view in the municipality of Sousa. And since local events have also been carried out at the regional and national levels, the issue covered here covers a much wider reality.
\end{abstract}

KEYWORDS: Fuel Prices; Consumer Protection; Social Impacts.

\title{
1 INTRODUÇÃO
}

Em maio de 2018 eclodiu no Brasil uma greve dos caminhoneiros em manifesto as altas dos preços dos combustíveis, deixando a nação em clima de instabilidade e imprevisibilidade. Uma das principais reclamações dos grevistas e da população em geral foi à frequente alteração nos preços dos combustíveis, em virtude da nova política de preços da Petrobras, conjuntura essa que levou caminhoneiros e demais profissionais que realizam o transporte de mercadorias paralisassem as suas atividades.

O presente trabalho se propõe a analisar a problemática da supracitada greve dos caminhoneiros, investigando os fatores que levaram ao ocorrido e as consequências advindas dele com ênfase nas condutas contrárias ao direito consumerista. O estudo dessa temática se faz devido à relevância social e econômica do mesmo para a coletividade e a nível local da mencionada paralisação.

De início foram trabalhados aspectos de âmbito nacional e os fatores que culminaram na referida paralisação dos caminhoneiros. Posteriormente analisaram-se as condutas ocorridas durante $o$ período da greve no que se refere à óptica da proteção ao consumidor. Por fim, analisaram-se os impactos de tais práticas na coletividade em aspecto geral e local. Almejando, assim mostrar a 
situação ocorrida no município de Sousa-PB e que se repetiu em diversas localidades pelo país.

\section{METODOLOGIA}

O Código de Defesa do Consumidor tem por objetivo resguardar os direitos dos consumidores como parte mais frágil nas relações comerciais. Para isso trata de práticas abusivas praticadas por vendedores e fornecedores de produtos e serviços em face de seus consumidores e as medidas que devem ser tomas caso tais ilegalidades venham a ocorrer.

O método de procedimento adotado foi o estudo de caso acerca dos ilícitos consumeristas identificados no município de Sousa, Paraíba. E quanto à técnica de pesquisa, adotou-se a bibliográfica, realizando um levantamento acerca dos combustíveis e do movimento grevista dos caminhoneiros, em âmbito nacional e posteriormente local. Também foram utilizadas matérias e posicionamentos de especialistas no assunto, bem como notas e dos de órgão oficiais.

Abordou-se o Código de Defesa do Consumidor e as condutas praticadas por postos de gasolina, principalmente, e como tais condutas violam as determinações do Código em questão e como os órgãos de defesa do consumidor atuaram para coibir os abusos ocorridos.

\section{FATORES APONTADOS PELOS ECONOMISTAS ACERCA DA PROBLEMÁTICA DA ALTA DOS PREÇOS DE COMBUSTÍVEIS}

Neste ponto se apresenta o pensamento de alguns especialistas na área da economia e em específico na questão dos combustíveis sobre os problemas socioeconômicos que ocorreram no período de paralisação das atividades dos caminhoneiros. E assim verificar os pontos gerais que culminaram na paralisação.

No Brasil já houveram protestos de caminhoneiros devido à insatisfação com os preços dos combustíveis, um exemplo foi o corrido em 2015, consoante o G1 (2015), nos meses de fevereiro e novembro, ocorreram protestos dos caminhoneiros que reivindicavam os altos preços dos combustíveis. Cabe demonstrar 
que o a insatisfação com a alta nos preços dos combustíveis não é recente, mas um problema quase que permanente. Contudo neste trabalho procuramos nos ater ao evento ocorrido em maio do presente ano.

O mercado dos derivados de petróleo do Brasil é livre desde 2002, entretanto a Petrobras comanda todo o refino nacional, sendo a responsável pelo abastecimento do mercado interno. A estatal determina os preços no mercado interno e praticava preços inferiores ao internacional, mesmo ao sofrerem reajustes nos preços da gasolina e do diesel. Sua política de preços é estabelecida de acordo com os objetivos e princípios estabelecidos pelo conselho de administração, sendo a União o maior acionista (ALMEIDA; OLIVEIRA; LOSEKANN, 2015).

A política de preços adotada pela Petrobras, a partir de julho de 2017, fez com que o preço dos combustíveis acompanhe a variação do dólar e o preço do barril de petróleo no mercado internacional, fazendo com que o mesmo venha aumentando substancialmente nos últimos meses. Segundo Borges (2018), a Petrobras adotou uma nova política de preços que vislumbrava seguir as alterações dos valores internacionais do petróleo. Essa política da Petrobras resultou em uma elevação de $55 \%$ do valor dos combustíveis no país. Segundo os manifestantes o preço do combustível saltou, em um espaço de tempo de um ano, cerca de mais de 50\% do valor (BBC, 2018).

No que se refere à política anterior de preços da Estatal, entre os anos de 2011 e 2015, a alteração internacional nos preços dos combustíveis não era diretamente repassada aos preços dos combustíveis no Brasil, era uma maneira de o governo controlar a alta da inflação. Tal situação levou à grande prejuízo na Petrobras, que passou de $\mathrm{R} \$ 75$ bilhões no final de 2014, tendo em vista que a estatal arcava com o que não era repassado ao consumidor. A referida política de preços é apontada como um dos principais responsáveis pelo alto endividamento da Petrobras, que no período chegou a US\$ 124 bilhões (MOTA, 2018).

Diante o exposto, a antiga política de preços adotada pela Petrobras pode ser considerada como um dos responsáveis pelo endividamento da empresa. E a atual política de preços, em que o preço final varia de acordo com a cotação internacional do barril de 
petróleo, vem causando instabilidade e insatisfação para o consumidor do produto.

Ainda no que tange ao valor do combustível trata pormenorizadamente a forma como é tabelado o preço e os tributos que incidem sobre o mesmo:

Os valores praticados pela Petrobras são aproximadamente um terço do preço pago pelo consumidor nos postos. Do total, $11 \%$ é o custo do etanol, que, por lei, deve compor $27 \%$ da gasolina comum, e $12 \%$ corresponde aos custos e lucro dos distribuidores, conforme os cálculos da Petrobras, que levam em conta a coleta de preços entre os dias 6 e 12 de maio em 13 regiões metropolitanas do país. Cerca de $45 \%$ são tributos, sendo $29 \%$ ICMS, recolhido pelos Estados, e $16 \%$ Cide e Pis/Cofins, de competência da União. Os tributos federais são cobrados como um valor fixo por litro - o de Pis/Cofins, por exemplo, é de $\mathrm{R} \$ 0,7925$ por litro de gasolina; a Cide, de $\mathrm{R} \$ 0,10$ por litro (MOTA, 2018).

Ou seja, o preço do combustível é uma somatória de impostos, dos encargos da produção e da própria lucratividade dos postos. E a política de preços adotada foi em virtude de sucessivos prejuízos nos cofres da Petrobras. Contudo percebe-se que tais informações não são conhecidas pela maioria da população, o que aumenta a revolta do consumidor em relação aos preços dos combustíveis.

Ainda conforme Mota (2018) foram pensadas duas maneiras para que o governo pudesse interferir na questão: diminuindo a incidência de tributos e mudando a política de preços da Petrobras. Contudo ambas as possibilidades não são adequadas de acordo com especialistas.

O governo federal cogitou ambas as possibilidades, entretanto após oposições da estatal e da equipe econômica do governo optou por zerar a incidência da Cide sobre o diesel, imposto que acaba por não influenciar tanto no preço final do produto (MOTA, 2018).

Após mais de uma semana de um clima de apreensão e instabilidade em quase todo o país por conta da paralisação, chega ao fim o movimento dos caminhoneiros autônomos, tendo atendidas algumas de suas demandas. E posteriormente com pronunciamento do Presidente da república repudiando e ordenando o uso das forças armadas para coibir aqueles que não aderiram ao acordo. 
Depois de reunião realizada no dia 27 de maio, na Casa Civil, a Associação Brasileira dos Caminhoneiros assinou acordo com o Governo e assim, pôr termo a greve dos caminhoneiros autônomos depois de promessa de atender a certas demandas destes. Entre elas foi estabelecida a redução de $\mathrm{R} \$ 0,46$ no preço do diesel, bem como a estabilização de seu preço por 60 dias, e após esses 60 dias o preço será reajustado a cada 30 dias, permitindo, assim, certa estabilidade para a cobrança do valor do frete (CARTA CAMPINAS, 2018). Desta forma encerrou-se a greve, no aguardo de que as reivindicações dos grevistas fossem concedidas e devidamente implantadas, a fim de também prevenir a ocorrência de eventos congêneres.

\section{VIOLAÇÕES CONSUMERISTAS PREVISTAS NO CDC}

O tema da defesa ao consumidor se encontra em algumas partes do texto constitucional, no corpo e nos Ato das Disposições Constitucionais Transitórias-ADCT, e especialmente no Título VIIDa Ordem Econômica e Financeira. A proteção ao Consumidor aparece como um dos princípios da Ordem Econômica: "Art. 170. A ordem econômica, fundada na valorização do trabalho humano e na livre iniciativa, tem por fim assegurar a todos existência digna, conforme os ditames da justiça social, observados os seguintes princípios: [...] V- defesa do consumidor" (BRASIL, 1988). E como tal deve perpassar todas as demais normas e medidas em relação ao consumidor, que deve ser respeitado e atendido em suas necessidades.

Com base nesta disposição constitucional temos ideia da importância da proteção ao consumidor para o adequado funcionamento da economia no geral. Para esse fortalecimento surgiu o Código de Defesa do Consumidor. Este como elo mais fraco ou hipossuficiente na relação consumerista necessita de um amparo maior por parte dos institutos legais, em especial para que seja evitado o aumento abusivo de preços por parte dos fornecedores.

A temática da defesa do consumidor também é tratada como direito fundamental e se encontra no inciso XXII do art. $5^{\circ}$ do Texto Constitucional: "o Estado promoverá, na forma da lei, a defesa do consumidor". Seguindo o disposto no art. 48 do ADCT diz que "O Congresso Nacional, dentro de cento e vinte dias da promulgação da Constituição, elaborará código de defesa do 
consumidor" (BRASIL, 1988). Seguindo esta determinação legal foi elaborado o referido código.

$\mathrm{O}$ art. $2^{\circ}$ do Código de Defesa do Consumidor-CDC, Lei $\mathrm{n}^{\circ}$ 8.078, conceitua o termo consumidor da seguinte maneira: "Consumidor é toda pessoa física ou jurídica que adquire ou utiliza produto ou serviço como destinatário final”. É aquele que compra para seu consumo próprio, que não é fornecedor de produto ou serviço.

O Código ainda prescreve: “Art. $4^{\circ}$ A Política Nacional das Relações de Consumo tem por objetivo [...] o respeito à sua dignidade, $[. .$.$] a proteção de seus interesses econômicos, a melhoria$ da sua qualidade de vida, bem como a transparência e harmonia das relações de consumo". Aqui é determinado o respeito ao consumidor nas suas demandas e o respeito a sua dignidade, buscando prevenir abusos pela parte mais forte da relação,vendedores e fornecedores.

O CDC aborda as práticas abusivas cometidas contra consumidores, as que se referem à questão dos abusos ocorridos este ano em decorrência da escassez de combustíveis nos postos são principalmente as seguintes: “Art. 39. É vedado ao fornecedor de produtos ou serviços, dentre outras práticas abusivas: [...] V - exigir do consumidor vantagem manifestamente excessiva; [...] X - elevar sem justa causa o preço de produtos ou serviços", Brasil, 1990.

Partindo desse pressuposto o inciso X é o que dá base para que os consumidores que se sentiram lesados de recorrerem ao órgão competente, o Programa de Proteção e Defesa do ConsumidorProcon, e prestarem a devida denúncia. E desta forma resguardar o direito desrespeitado no período de escassez de mercadorias, em especial de combustíveis, evitando demasiados ganhos em virtude da situação de calamidade no período.

\section{IMPACTOS SOCIAIS DECORRENTES DA GREVE DOS CAMINHONEIROS}

Nas mais diversas localidades espalhadas pelo país ocorreram ilegalidade no período em questão, em especial o aumento arbitrário dos preços dos combustíveis no período de escassez por parte de diversos postos de gasolina, situação esta amplamente divulgada pela mídia.

$\mathrm{O}$ órgão competente para resolver as demandas levadas pelos consumidores é o Programa de Proteção e Defesa do Consumidor- 
Procon, que existente em todo o país. Contudo neste trabalho o enfoque será na atuação dele no município de Sousa-PB.

Durante o período mais crítico da paralisação houve falta de combustível em diversos postos da cidade. A escassez levou os donos de postos de combustíveis a elevar demasiadamente os preços dos mesmos. Tal prática viola frontalmente a legislação de proteção ao consumidor, pois a população local tinha a possibilidade de abastecer em apenas em poucos locais e para satisfazer sua necessidade pelo produto pagariam o preço necessário, mesmo que fosse mais o dobro do normal.

Diante desta situação, consumidores apresentaram denuncia ao Procon tendo em vista a gravidade do ocorrido e da necessidade de restabelecer o equilíbrio dessa relação de consumo e a necessidade de atuação do Procon para resguardar seus direitos e aplicar as medidas cabíveis aos infratores.

A seguir é apresentada uma notificação do referido órgão de Proteção Consumerista em desfavor de um posto de combustível da cidade, apresentando os direitos violados e as medidas que devem ser tomas para que a situação se regularize:

NOTIFICAÇÃO (URGENTE)

Sousa-PB, 08 DE JUNHO DE 2018

$[\ldots]$

ASSUNTO: CUMPRIMENTO DA PORTARIA N/ 760/2018REPASSE DE DESCONTO NO VALOR DO DIESEL-ENVIO DE DOCUMENTOS - PRÁTICAS ABUSIVAS - ELEVAÇÃO SEM JUSTA CAUSA DOS PREÇOS-VANTAGEM MENIFESTAMENTE INDEVIDA

$[\ldots]$

CONSIDERANDO que o Código de Defesa do Consumidor determina como prática abusiva em seu artigo 39, V e X e obtenção de vantagem manifestamente excessiva do consumidor e elevar sem justa causa o preço de produtos e serviços e que estes artigos devem ser lidos em consonância com o art. $5^{\circ}$ XXXII e 170, V da Constituição Federal;

$[\ldots]$ 
CONSIDERANDO ser princípio básico do consumidor e transparência nas relações de consumo (art. 4/ do CDC), bem como a boa-fé nas relações de consumo ( $\operatorname{art} .4^{\circ}$ do $\mathrm{CDC}$ ); $[\ldots]$

CONSIDERANDO que a revenda deverá nos novos estoques de DIESEL que adquirir a partir da medida publicada no Diário Oficial da União realizar a desconto anunciado pelo Governo Federal;

CONSIDERANDO que a cobrança de valores abusivos em relação a alguns produtos por parte do comércio varejista, conforme relatos realizados por consumidores e pela imprensa, pode caracterizar, também, crime contra as relações de consumo, passível sanção administrativa e penal;

\section{$[\ldots]$}

A notificação realizada pelo PROCON apresenta uma série de determinações legais de defesa do consumidor, como o direito a obtenção de informações sobre os produtos e a vedação ao aumento injustificado dos preços, muitas delas apresentadas no tópico anterior e violadas por vários postos de combustíveis do município de Sousa.

\section{RECOMENDAMOS:}

Que de acordo com o art. 10 da Portaria $n^{\circ} 760$ de junho de 2018, os postos devem informar de forma CLARA e OSTENSIVA, por meio de cartaz, placa, faixa ou similar, o valor da redução do preço do litro do diesel para os consumidores finais, demonstrando nesse informativo o valor de revenda para o consumidor final no dia 21 de maio de 2018 e o valor do diesel a partir de $1^{\circ}$ de junho de 2018 , sob pena de multa administrativa;

Que o posto de combustível e a revenda de GLP não pratique aumento injustificado do preço;

Observe o princípio do equilíbrio contratual e da boa-fé;

Ostentar adequadamente o preço praticado para os produtos disponíveis em estoque, bem como, como assim o faça o limite quantitativo por consumidores; 
Adeque os preços do DIESEL assim que publicadas as diferenças pelo Governo Federal;

O órgão de defesa do consumidor no uso de suas atribuições determina que o estabelecimento exponha os preços praticados ao consumidor, restabelecendo, assim o equilíbrio nas relações.

NOTIFICA o estabelecimento notificado a fornecer no prazo de $48 \mathrm{~h}$ a contar do recebimento desta notificação as seguintes informações por escrito no endereço do PROCON MUNICIPAL DE SOUSA [...]:

TODAS AS NOTAS FISCAIS DE COMPRA DE TODOS OS COMBUSTÍVEIS LÍQUIDOS E GLP DESDE 18/05/2018; OS VALORES QUE PRATICOU, COMPROVANDO-OS DURANTE OS DIAS A PARTIR DE 18/05/2018;

Por derradeiro, informa-se que a recusa à prestação de informações poderá ensejar a aplicação da disposição do $\$ 2^{\circ}$ do art. 33 do Decreto Federal n. 2.181/97, que caracteriza o crime de desobediência previsto no art. 330 do Código Penal

Por fim a notificação demonstra as punições cabíveis em caso de descumprimento, reforçando assim, a força atuante do órgão em defesa dos direitos dos consumidores lesados com as irregularidades cometidas.

\section{CONCLUSÃO}

Com base nas informações apresentadas notou-se que a greve dos motoristas em maio de 2018 se deu em decorrência da insatisfação da população em geral com a nova política de preços apresentada na gestão de Pedro Parente na Petrobrás em estabelecer o preço do petróleo de acordo coma s oscilações do mercado internacional, levando a sucessivos aumentos no preço do combustível.

Bem como devido à insegurança e falta de confiança da população quanto aos seus governantes e a clima de instabilidade política e econômica que vem se desenvolvendo ao longo dos últimos anos, ou seja, o problema não é recente. Sendo assim, as insatisfações da classe dos caminhoneiros já haviam sido manifestadas desde 2015, por meio de protestos, acerca da situação enfrentada por estes com relação aos aumentos dos combustíveis. 
A greve se encerrou com algumas das reivindicações dos grevistas atendidas, podendo citar: congelamento do valor do combustível por 60 dias, reajustes a cada 30 dias, extinção de cobranças de pedágios em rodovias.

O Código de Defesa do Consumidor, visando à proteção do mesmo atua por meio do PROCON para punir infratores que estão lesando e ferindo os direitos da população consumerista, como foi demonstrada a atuação do referido órgão e sua importância no Direito do Consumidor, coibindo as irregularidades cometidas por comerciantes e fornecedores.

Dentre o período de greve foi observado alguns impactos que afetaram diretamente a sociedade e a economia do país. Pode-se mencionar: a falta de combustíveis em postos e estes elevando os preços sob o combustível restante, as diminuições das frotas dos transportes públicos, adiamentos e cancelamentos de vôos, setores de produção paralisados, falta ou insuficiência de alimentos, óbito de animais pela falta de alimentação, entre outros.

O objetivo desse trabalho foi apontar os impactos da greve dos caminhoneiros à luz do código de defesa do consumidor e a atuação do Procon no Município de Sousa-PB. O estudo se refere a uma pesquisa qualitativa com base no levantamento de informações para a fundamentação teórica sobre os impactos da greve dos caminhoneiros. Assim, conclui-se que os objetivos do trabalho foram alcançados.

\section{REFERÊNCIAS}

ALMEIDA, Edmar Luis Fagundes de; OLIVEIRA, Patricia Vargas de; LOSEKANN, Luciano. Impactos da contenção dos preços de combustíveis no Brasil e opções de mecanismos de precificação. Revista de Economia Política, São Paulo, v. 35, n. 3, p.531-556, set. 2015. Disponível em: <http://www.scielo.br/pdf/rep/v35n3/1809-4538-rep-35-0300531.pdf> .Acesso em: 30 set. 2018

BBC: Greve dos caminhoneiros: a cronologia dos 10 dias que pararam o Brasil. Disponível em: <https://www.bbc.com/portuguese/brasil44302137\#orb-banner>.Acesso em: 12 de jul de 2018.

BORGES, Rodrigo. El País:Greve dos caminhoneiros: como se formou o nó que levou à paralisação. Disponível em: <https://brasil.elpais.com/ brasil/2018/05/24/economia/1527177800_693499.html>. Acesso em: $12 \mathrm{de}$ jul de 2018. 
BRASIL. Lei $\mathbf{n}^{0}$. 8.078, de 11 de setembro de 1990.Código de Defesa do Consumidor. Dispõe sobre a proteção do consumidor e dá outras providências. Disponível em: <http://www.planalto.gov.br/ccivil_03/ Leis/L8078.htm>. Acesso em: 12 de jul de 2018.

BRASIL. Constituição Federal de 1988. Promulgada em 5 de outubro de 1988. Disponível em <http://www.planalto.gov.br/ccivil_03/constituicao/ constituicao.htm>. Acesso em: 12 jul de 2018.

CARTA CAMPINAS: Associação dos caminhoneiros diz que reivindicações foram atendidas e pede fim da greve. Disponível em: $<$ http://cartacampinas.com.br/2018/05/associacao-dos-caminhoneiros-dizque-reivindicacoes-foram-atendidas-e-pede-fim-da-greve/>. Acesso em: 14 de jul de 2018.

G1: Protesto dos caminhoneiros bloqueia estradas pelo país. Disponível em: $<$ http://g1.globo.com/economia/noticia/2015/02/protesto-de-caminhoneirosbloqueia-estradas-pelo-pais.html>. Acesso em: 12 de jul de 2018.

MOTA, Camilla Veras. BBC: 6 perguntas para entender a alta nos preços na gasolina e no diesel. Disponível em: <https://www.bbc.com/ portuguese/brasil-44217446>. Acesso:13 de jul de 2018.

PROCON SOUSA. Disponível em: <https://www.facebook.com/proconsousa>. Acesso em: 15 de jul de 2018.

SOARES, João. Deutsche Welle: Os impactos da greve dos caminhoneiros na economia. Disponível em: <https://www.dw.com/ptbr/os-impactos-da-greve-dos-caminhoneiros-na-economia/a-43967170>.

Acesso em: 12 de jul de 2018. 